\title{
Particle Size and Hydration Properties of Dried Apple Pomace: Effect on Dough Viscoelasticity and Quality of Sugar-Snap Cookies
}

\author{
Andrés F. Rocha Parra ${ }^{1} \cdot$ Marta Sahagún $^{2} \cdot$ Pablo D. Ribotta ${ }^{3} \cdot$ Cristina Ferrero $^{1} \cdot$ Manuel Gómez $^{2}$
}

Received: 19 April 2018 / Accepted: 28 March 2019 / Published online: 19 April 2019

(C) Springer Science+Business Media, LLC, part of Springer Nature 2019

\begin{abstract}
Apple pomace (AP) is a by-product of the juice industry, rich in dietary fiber $(45.06 \%)$, which is generated in large quantities. The objectives of the present work were to evaluate the effect of the particle size and the level of replacement with AP on the quality of sugar-snap cookies. Dehydrated AP was ground to three different particle sizes $(\mathrm{d}(4,3)=362,482,840 \mu \mathrm{m})$ to substitute $15 \%$ and $30 \%$ of wheat flour in cookie formulations. The quality of dough and cookies was evaluated in terms of rheological properties, color, texture, and global acceptability of the final product. When the AP particle size decreased, the water absorption properties (WHC, WBC) were higher (33 and 10\% respectively for the lowest and the highest particle size). For both replacement levels, the smallest particle size $(362 \mu \mathrm{m})$ led to the highest dynamic moduli of dough. The spread ratio (SR) of the cookies diminished when the particle size decreased (from 6.4 to 4.8 corresponding to AP840 and AP362 respectively). The lowest SRs were obtained for the $30 \%$ replacement level except for AP362. When employing AP with the largest particle size $(840 \mu \mathrm{m})$, the cookies were less hard $(48.7 \mathrm{~N})$. The addition of AP to sugar-snap cookies led to higher global acceptability scores than for control cookies. The sensory attribute that most differentiated the cookies with AP was their pleasant taste being the taste score always higher than the control one.
\end{abstract}

Keywords By-product $\cdot$ Bagasse $\cdot$ Dietary fiber $\cdot$ Hydration properties $\cdot$ Cookie quality

\section{Introduction}

The industry of fruit juice and other derivatives such as nectars and soft drinks generates a large amount of by-products that can harm the environment, because they are generally prone to microbial deterioration. Therefore, the efficient utilization of these by-products, with low cost and environmentally friendly processes, is increasingly important (Schieber et al. 2001). They can be recovered and used as a value-added ingredient in different products since they provide dietary fiber, as well as bioactive compounds such as polyphenols and essential oils (Elleuch et al. 2011).

Andrés F. Rocha Parra

andresfelipe2484@gmail.com

1 CIDCA, Facultad de Ciencias Exactas, CCT La Plata (CONICET), Universidad Nacional de La Plata, 47 y 116, $1900 \mathrm{La}$ Plata, Argentina

2 Food Technology Area, College of Agricultural Engineering, University of Valladolid, 34004 Palencia, Spain

3 CONICET, Facultad de Ciencias Agropecuarias, Universidad Nacional de Córdoba, Av. Valparaíso s/n, 5000 Córdoba, Argentina
Among the main by-products of fruit processing generated worldwide, those from citrus (15 million tons/year), grape (7 million tons/year), and apple (4 million tons/year) stand out (Lin et al. 2013). In the world production of apple, $25-30 \%$ is destined for processing, the concentrated apple juice being the main product (65\%) (Bhushan et al. 2008). The apple juice industry generates large quantities of apple pomace (AP), which is the product obtained after juice extraction $(25-30 \%$ of the total weight of the fresh apple), consisting mainly of pulp/peel (95\%), seeds (2-4\%), and stem (1\%), according to the juice extraction process (O'shea et al. 2012). This byproduct is characterized by its high content in carbohydrates and dietary fiber, and significant amounts of phenolic compounds (Leyva-Corral et al. 2016; Dhillon et al. 2012). Apple fiber is mainly composed of cellulose $(43.6 \%)$, hemicellulose (24.4\%), lignin (20.4\%), and pectins (11.7\%) (Nawirska and Kwaśniewska 2005).

Dietary fiber intake for adults should be $25 \mathrm{~g} /$ day for a diet $2000 \mathrm{Kcal} /$ day (ADA Report 2002; WHO Technical Report 2003). For children older than 2 years, it is recommended an amount of fiber equal to their age plus $5 \mathrm{~g} /$ day (ADA Report 2002). In coincidence, FAO/WHO recommends $25 \mathrm{~g} /$ day in order to help preventing diet-related chronic diseases (WHO 
Technical Report 2003). Since there is an increasing concern respect to reach adequate levels of fiber intake, the developing of fiber-enriched products and the assessment of new sources of fiber have gained growing interest.

Apple pomace has been used in baked goods such as bread, cakes, and cookies (Quiles et al. 2016; Sudha et al. 2016; Jung et al. 2015; Rocha Parra et al. 2015a). The baked products that are more suitable for the use of these by-products are cookies and cakes because they usually include appreciable amounts of sugar and fat in their composition, thus masking a little the undesirable flavors. Besides, in the particular case of cookies is not necessary to develop a gluten network, and the negative effects of reducing the gluten level by substituting wheat flour by another ingredient are not so important (Gómez and Martinez 2017).

Different works on cookies with the addition of AP have been reported (Jung et al. 2015; Kohajdová et al. 2014; Singh et al. 2012). In these works, wheat flour has been replaced with apple pomace in quantities ranging from 5 to $25 \%$, and AP with particle sizes between 200 and $500 \mu \mathrm{m}$ have been assayed. In general, these authors found that the replacement of wheat flour by AP in cookies produces two effects, the first one is the reduction of the spread ratio and the second one, the reduction of the hardness with respect to the control (without apple pomace). However, they worked with a single particle size. The particle size, as well as other physical properties such as porosity, and the specific surface can be altered according to the process that is used to prepare the by-product. Among the different procedures, grinding can modify the physical properties of the fiber and therefore change the hydration properties thereof (Guillon and Champ 2000). It is important to take this point into account, because different particle sizes will alter the hydration properties of the system in a different way and therefore influence the quality parameters of the processed product. Several authors have reported the effect of the particle size on the hydration properties of AP (Liu et al. 2011; Grover et al. 2003). In cookies, it has been found that a smaller particle size in the flour used increases the hardness, in comparison with flours of greater particle size (Dayakar Rao et al. 2016; Zucco et al. 2011; Mancebo et al. 2015).

The objective of this work was to evaluate the effect of apple pomace of three particle sizes $(\mathrm{d}(4,3)=362,482$, $840 \mu \mathrm{m})$ at two replacement levels (15 and 30\%) on the quality of sugar-snap cookies, in terms of dough rheology, quality characteristics, and sensory evaluation of the final product.

\section{Materials and Methods}

\section{Materials}

Crude apple pomace provided by Jugos SA (Villa Regina, Rio Negro, Argentina), wheat flour (WF) (11.42 g/100 g moisture;
$10.43 \mathrm{~g} / 100 \mathrm{~g}$ protein) supplied by Harinera Castellana S.L. (Medina del Campo, Valladolid, Spain), white sugar (AB Azucarera Iberia, Valladolid, Spain), 100\% vegetable margarine (Argenta crema, Puratos, Barcelona, Spain), sodium bicarbonate (Manuel Riesgo S.A., Madrid, Spain), and local tap water were used. Vegetable margarine contained refined palm oil, sunflower palm oil, water, emulsifiers (mono and diglycerides of vegetable fatty acids), sorbic acid, color, and flavoring agents.

\section{Methods}

\section{Apple Pomace Treatment and Characteristics}

For drying apple pomace, a forced convection oven (ESTIGIA, La Plata, Argentina) at $50{ }^{\circ} \mathrm{C}$ was employed for $24 \mathrm{~h}$. Dried apple pomace was ground with a sieve size of $0.75 \mathrm{~mm}$ (Cross Beater Mill, Pulverisette 16, Idar-Oberstein, Germany). Composition was determined according to AOAC methods (1990): moisture, method 964.22; protein, method 979.09; ash, method 923.03; total dietary fiber, method 991.4; fat, method 920.39. Carbohydrates were calculated by difference. Assays were performed in duplicate.

The powder obtained was sterilized at $121^{\circ} \mathrm{C}$ for $20 \mathrm{~min}$ in a steam autoclave (VZ, Ciudadela, Argentina) to eliminate yeasts and molds (natural flora). Afterwards, the AP was reground using two different ring sieves $(0.5 \mathrm{~mm}$ and $0.2 \mathrm{~mm})$ (Ultra-Centrifugal Mill, Retsch, ZM 200, Hann, Germany). The particle size of ground AP was determined as the volume fraction-length mean diameter $(\mathrm{d}(4,3))$ using a laser diffraction technique with a Malvern Mastersizer 3000 E (Malvern Instruments Ltd., Malvern, Worcestershire, UK). The refractive index used was 1.54. The sample was automatically suspended by the equipment. Each sample was measured three times to obtain the mean. For color determination $1.5 \mathrm{~g}$ of each powder was weighed in a glass capsule $2 \mathrm{~cm}$ high and $9 \mathrm{~cm}$ in diameter; the measurements were made in triplicate, with a Minolta CN-508i spectrophotometer (Minolta, Co. LTD, Tokyo, Japan) using the D65 illuminant with the 2standard observer. Results are expressed in the CIE $L^{*}, a^{*}$, $b^{*}$ color space. Assays were performed in triplicate.

\section{Hydration and Oil Absorption Properties of AP and Wheat Flour}

The different fractions of apple pomace and wheat flour were characterized by their hydration and oil absorption properties. Water holding capacity (WHC) is defined as the grams of water retained per gram of sample when not submitted to stress. It was determined according to the AACC method 88-04 (AACC 2012). Five grams of each sample were dispersed in $100 \mathrm{~mL}$ distilled water in a graduated cylinder and left to rest for $24 \mathrm{~h}$. Then, the excess water was removed and 
the swelled solid was weighed; the retained water was calculated by difference. Water binding capacity (WBC) is expressed as the grams of water that remain bound to the sample after employing low-speed centrifugation. It was determined upon AACC method 56-30.01 (AACC 2012). Five grams of each sample were mixed with $25 \mathrm{~mL}$ of distilled water in a Falcon tube and then centrifuged $(2000 \times g$, $10 \mathrm{~min}$ ). All the assays were performed in duplicate.

The oil absorption capacity (OAC) was determined according to Lin et al. (1974). It was calculated as grams of oil bound per gram of sample on dry basis. One hundred milligrams of each sample were mixed with $1 \mathrm{~mL}$ of vegetable oil in an Eppendorf tube. The mixture was well stirred $(30 \mathrm{~min})$ in a vortex mixer and then centrifuged $\left(3000 \times g, 4{ }^{\circ} \mathrm{C}, 10 \mathrm{~min}\right)$. Then, the supernatant was extracted with a pipette; the tubes were overturned for $25 \mathrm{~min}$ to drain the oil and the residue was weighed. This assay was performed by triplicates.

\section{Cookie Preparation}

Cookies were prepared according to the procedure of Mancebo et al. (2018) that is schematized in Fig. 1. Seven different cookie formulations (control and two replacement

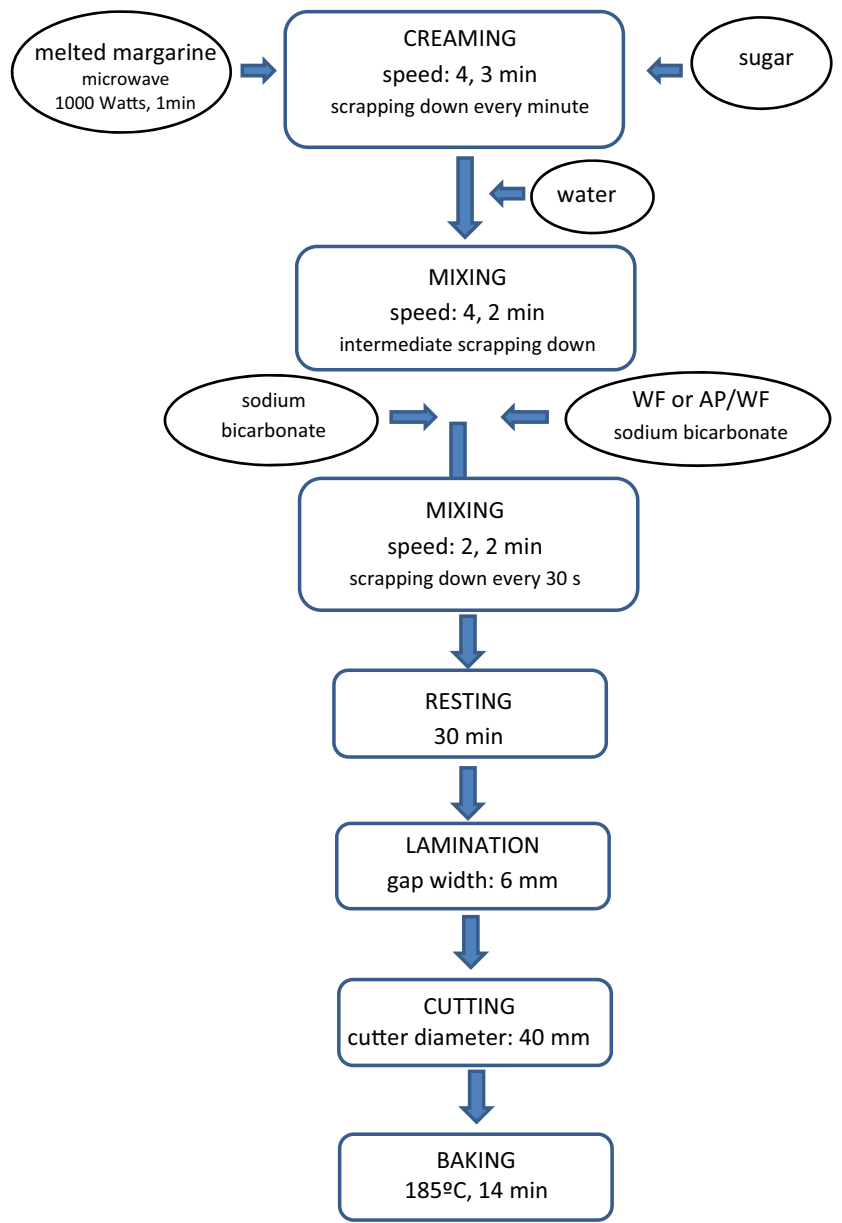

Fig. 1 Flow-sheet for cookie preparation based on Mancebo et al. (2018) levels: $15 \%$ and $30 \%$ for each particle size of AP) were prepared. Each cookie formulation was made by duplicate. The same amounts of ingredients were used in all cases but water varied in order to reach a final moisture content of $15 \%$. The amounts of the ingredients (on $100 \mathrm{~g}$ dough basis) were WF or AP-WF mixture, $43.3 \mathrm{~g}$; sugar, $31.2 \mathrm{~g}$; margarine, $19.4 \mathrm{~g}$; water, $5.2 \mathrm{~g}$, and sodium bicarbonate, $0.9 \mathrm{~g}$. The cookie used as control sample was made with wheat flour and without AP. Each batch consisted of 18 cookies. A Kitchen Aid 5KPM50 mixer (Kitchen Aid, Benton Harbor, MI, USA) was used and the pieces of dough were laminated in a Salva L-500-J sheeter (Salva, Lezo, Spain). An electric modular oven was employed for baking. Cookies were preserved in polypropylene bags at $20{ }^{\circ} \mathrm{C}$ until analysis.

\section{Dough Rheology Properties}

Rheological measurements were taken using a controlled strain rheometer (Thermo Scientific Haake RheoStress1, Thermo Fisher Scientific, Schwerte, Germany) with parallelplate geometry $(60-\mathrm{mm}$ diameter titanium serrated plate-PP60 Ti) with a 3-mm gap and a Phoenix II P1- C25P water bath for temperature control (set at $25{ }^{\circ} \mathrm{C}$ ). Before measuring, the dough was left resting for $800 \mathrm{~s}$. The linear viscoelasticity region (LVR) was determined through a stress sweep range of $0.1-100 \mathrm{~Pa}$ at a constant frequency of $1 \mathrm{~Hz}$. On the basis of the results obtained, a stress value included in the LVR was used in a frequency sweep test at $25^{\circ} \mathrm{C}$ with a frequency range of $0.1-10 \mathrm{~Hz}$. Average stress values for frequency sweeps were $4 \mathrm{~Pa}$ for control dough, $8 \mathrm{~Pa}$ for dough with $15 \%$ replacement, and $15 \mathrm{~Pa}$ for dough with $30 \%$ replacement. Values of elastic modulus ( $\left.G^{\prime}[\mathrm{Pa}]\right)$, viscous modulus $\left(G^{\prime \prime}\right.$ $[\mathrm{Pa}])$, and tangent $\delta\left(G^{\prime \prime} / G^{\prime}\right)$ were obtained for different frequency values $(\omega[\mathrm{Hz}])$. Samples were analyzed in duplicate.

\section{Cookie Properties}

After cooling during an hour at room temperature, six cookies of each formulation were individually weighed. A caliper was used for measuring the diameter and thickness of the cookies. The average diameter or width of each cookie was calculated as the mean of two perpendicular diameters. With these six mean values, the average width $(W)$ was determined. The average thickness $(T)$ was also calculated. The spread ratio (SR) of the cookies was expressed as the average width $(W)$ divided by the average thickness $(T)$.

The texture properties of cookies were studied by a threepoint bending test, carried out at room temperature with a TAXT2 texture analyzer (Stable Microsystems, Surrey, UK) controlled by the Texture Expert software. Eight cookies of each formulation were measured $24 \mathrm{~h}$ after baking. The experiment conditions were the same used by Mancebo et al. (2018): distance between supports, $30 \mathrm{~mm}$; trigger force, $5 \mathrm{~g}$; probe 
travel distance, $30 \mathrm{~mm}$; pretest speed, $1.0 \mathrm{~mm} \mathrm{~s}^{-1}$; test speed, $2.0 \mathrm{~mm} \mathrm{~s}^{-1}$; and posttest speed, $10.0 \mathrm{~mm} \mathrm{~s}^{-1}$. The maximum force $(\mathrm{N})$ and the displacement at rupture $(\mathrm{mm})$ were measured.

The surface color of six sugar-snap cookies from each formulation was measured at the center point of the upper surface with a Minolta CN-508i spectrophotometer (Minolta, Co. LTD, Tokyo, Japan) using the D65 illuminant with the 2standard observer. Results are expressed in the CIE $L^{*}, a^{*}$, $b^{*}$ color space.

\section{Cookie Acceptability}

For the hedonic sensory evaluation of cookies, 63 volunteers (19 males, 44 females) that were regular cookie consumers were invited to perform the test. The range of ages was 1864 years with the following distribution: $78 \%$ between 18 and 24 years old, $17 \%$ between 25 and 34 years old, and 5\% elder than 35 years. The attributes that were evaluated were appearance, odor, texture, taste, and overall appreciation on a ninepoint hedonic scale. The scale of values ranged from "like extremely" to "dislike extremely" corresponding the highest and lowest scores to "9" and " 1 " respectively (Mancebo et al. 2015). Samples were analyzed 1 day after baking. Whole cookies were labeled with four-digit random numbers and served in random order. Each evaluator received four cookies on a dish: the control cookie and cookies with AP362, AP482, and AP840at the replacement level of $15 \%$.

\section{Statistical Analysis}

The analysis of variance (ANOVA) was applied, and post Tukey's HSD was used to assess significant differences (confidence interval of 95\%). The analysis was performed using Statgraphics Plus V5.1 software (Statpoint Technologies, Warrenton, USA).

\section{Results and Discussion}

\section{Apple Pomace Powder Characteristics}

The dried AP was a slightly brown and aromatic powder. Its composition was (on $100 \mathrm{~g}$ basis) as follows: moisture, $12.1 \pm$ $0.2 \mathrm{~g}$; protein, $4.74 \pm 0.04 \mathrm{~g}$; ash, $1.30 \pm 0.01 \mathrm{~g}$; total dietary fiber, $45.1 \pm 0.1 \mathrm{~g}$; fat, $1.86 \pm 0.01 \mathrm{~g}$; and carbohydrates different from fiber (calculated by difference), $34.9 \mathrm{~g}$. Results of the measurements of particle size distribution are shown in Fig. 2. Besides the lowest mean particle size, the more ground apple pomace $(0.2 \mathrm{~mm}$ sieve $)$ exhibited a more narrow range of sizes. The three obtained AP powders had the following (d(4,3)): $840 \mu \mathrm{m}, 482 \mu \mathrm{m}, 362 \mu \mathrm{m}$ and were named AP840, AP482, and AP362, respectively.

\section{Apple Pomace and Dough Characteristics}

The particle sizes and the physical characteristics of the different fractions of ground AP are shown in Table 1. Apple pomace exhibited enhanced hydration capacity compared to WF as shown by the higher values of WHC and WBC. In a previous work, it was reported that another hydration property of AP, the water imbibing capacity (WIC), which is governed by capillary forces was much higher than WIC of the refined rice flour or cassava starch. This behavior was related to the great fiber content of AP, which is rich in cellulose, pectin, and hemicelluloses (Rocha Parra et al. 2015b).

For AP, WHC values ranged from 6.7 to 8.93 and WBC increased from 5.16 to 5.63 ; both parameters showed a significant positive correlation between them $(r=0.9750, p<0.05)$. When AP of different particle sizes was compared, it was found that as the particle size decreased, the hydration capacities (WHC, WBC) were significantly higher $(p<0.05)$. The increase of hydration properties at lower particle sizes has been reported for various types of flours such as chestnut (Ahmed et al. 2016) and sorghum (Dayakar Rao et al. 2016) and also for carrot pomace (Chau et al. 2007). This increase can be associated with the greater surface area (De La Hera et al. 2013; Chau et al. 2007; Robertson and Eastwood 1981). On the other hand, the particle size does not have a clear influence on the OAC.

As expected, the highest $L^{*}$ and the lowest values for $a^{*}$ and $b^{*}$ were shown by WF. The AP characteristic brown color can be attributed to the partial caramelization of apple sugars during the drying process, in addition to Maillard reactions that occur between proteins and sugars as explained by Caparino et al. (2012). A significant effect of the particle size on $L^{*}$ of AP was found, with values increasing from 40.1 to 54.1 (for AP840 and AP362, respectively). Luminosity values were in agreement with those reported for apple pomace by other authors (Lavelli and Kerr 2012). The values of $a^{*}$ is negative for green and positive for red, and $b^{*}$ is negative for blue and positive for yellow. The values of $a^{*}$ were not significantly different among AP samples, but a tendency to increase the reddish color was found as the particle size decreased. AP840 had the lowest value of $b^{*}(10.5)$ and there was a significant difference $(p<0.05)$ when compared to AP362, which presented the highest value of $b^{*}$ (18.18). The changes observed in $L^{*}$ and $b^{*}$ values could be attributed to the oxidation of certain components, which would be more favored in the product with the smaller particle sizes due to the greater surface that is exposed. The color of the powders made up of larger particles was less uniform than that of samples with smaller particles, leading to higher standard deviations for AP840 values.

The mechanical spectra of the doughs are shown in Fig. 3. For all samples $G^{\prime}>G^{\prime \prime}$, with a slight dependence on frequency, indicating that all doughs exhibited a predominantly solid 
Fig. 2 Particle size distribution for AP powders for AP840 (whole line), AP482 (dashed line), AP362 (dotted line)

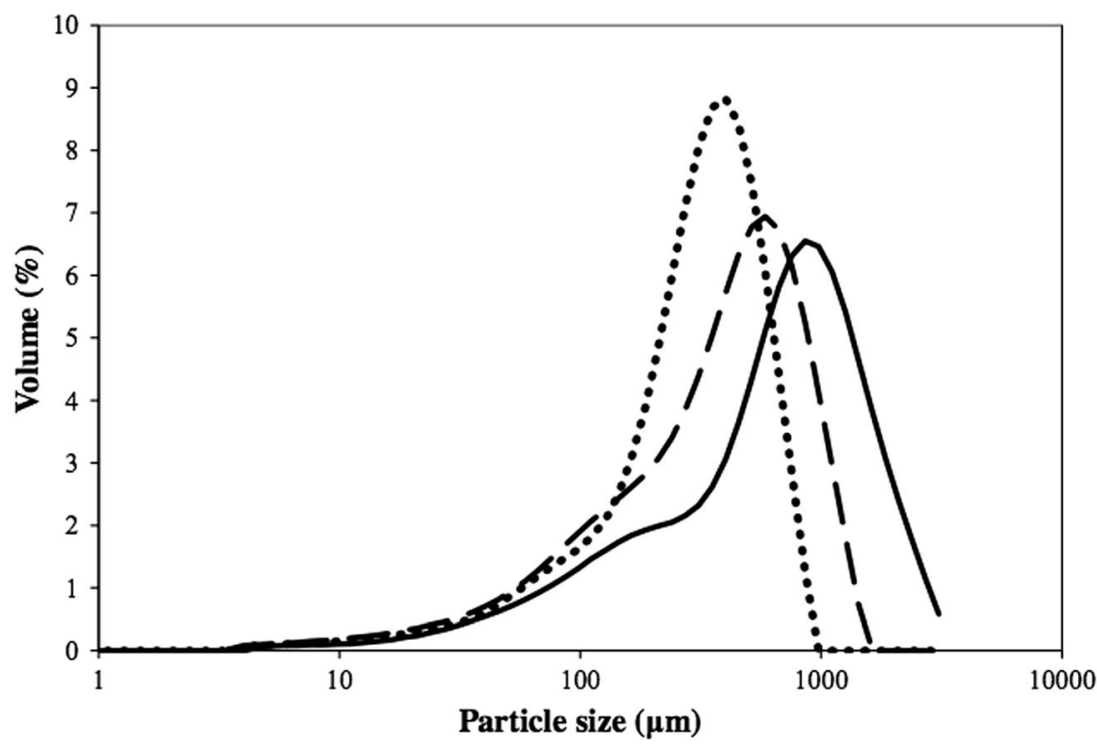

behavior. The type of viscoelastic behavior of doughs was affected by the addition level and particle size of AP. The dynamic moduli were higher for doughs with AP than for WF dough. Besides, for the highest substitution level (30\%), the dynamic moduli were higher than for the lowest level of AP. Mancebo et al. (2018), Laguna et al. (2014) also found an increase in $G^{\prime}$ and $G^{\prime \prime}$ values when partially substituting wheat flour by insoluble fibers. Apple pomace has a high content of total dietary fiber, which is mostly insoluble (Rosell et al. 2009; Sudha et al. 2007). Figures $3 \mathrm{~b}$ and $\mathrm{c}$ show the influence of the particle size on the dynamic moduli at each level of substitution with AP: when the particle size decreases the value of both moduli increases. When WF was substituted with AP, the value of the loss tangent decreased, and for the two levels of added AP (15\% and $30 \%$ ), it was found that as the particle size decreases, the loss tangent decreases, indicating that the elastic behavior predominates over the viscous one.

There are discrepancies about the influence of particle size on the rheological behavior of dispersed systems. Mancebo et al. (2015) found that the dough elastic moduli of gluten-free sugar-snap cookies prepared with different flours (yellow maize, precooked yellow maize, buckwheat, teff and shortgrain, and long-grain rice flour) increased when the flour particle size decreased. Mancebo et al. (2018) also stated that in the case of insoluble fibers, besides the influence of hydration properties, the particle size and geometry are important factors influencing dough rheology. These authors found that the addition of pea and potato fibers led to cookie doughs with lower dynamic moduli $G^{\prime}, G^{\prime \prime}$, and $G^{*}$ than coarse bamboo fibers, that were lengthier and more flat. However, opposite trends have been reported by some authors (Petrović et al. 2015; Moreira et al. 2010) who found that the larger particle sizes in defatted wheat germ flour and chestnut flour increased the value of the dynamic moduli $\left(G^{\prime}, G^{\prime \prime}\right)$ in oscillatory assays. This lack of agreement in the results from different researches could be caused by the differences between the materials assayed in each case and the particular way they interact with other components of the system, particularly water. In the present work, AP362 showed higher water and oil absorption capacities than AP systems with larger particle sizes (Table 1), which could lead to more interaction with water and fat in cookie dough and consequently, higher modulus values.

\section{Cookie Characteristics}

In Fig. 4, the visual characteristics of cookies can be observed, and the physical characteristics are summarized in Table 2. Snapcookie quality can mainly be described by two parameters, the

Table 1 Wheat flour (WF) and apple pomace (AP) hydration properties and oil absorption capacity

\begin{tabular}{llllllll}
\hline & $\mathrm{d}(4,3)(\mu \mathrm{m})$ & WHC & WBC & OAC & $L^{*}$ & $a^{*}$ & \multicolumn{2}{c}{$b^{*}$} \\
\hline WF & $95 \pm 1 \mathrm{a}$ & $1.53 \pm 0.01 \mathrm{a}$ & $1.94 \pm 0.02 \mathrm{a}$ & $2.02 \pm 0.02 \mathrm{ab}$ & $90.0 \pm 1 \mathrm{c}$ & $-0.17 \pm 0.01 \mathrm{a}$ & $8.4 \pm 0.3 \mathrm{a}$ \\
AP840 & $840 \pm 2 \mathrm{~d}$ & $6.7 \pm 0.3 \mathrm{~b}$ & $5.16 \pm 0.05 \mathrm{~b}$ & $1.9 \pm 0.1 \mathrm{a}$ & $40.1 \pm 4.1 \mathrm{a}$ & $6.5 \pm 1.2 \mathrm{~b}$ & $10.5 \pm 2.7 \mathrm{ab}$ \\
AP482 & $482 \pm 2 \mathrm{c}$ & $6.8 \pm 0.3 \mathrm{~b}$ & $5.3 \pm 0.2 \mathrm{bc}$ & $2.1 \pm 0.1 \mathrm{ab}$ & $48.1 \pm 4.6 \mathrm{ab}$ & $7.39 \pm 0.03 \mathrm{~b}$ & $14.8 \pm 1.5 \mathrm{bc}$ \\
AP362 & $362 \pm 6 \mathrm{~b}$ & $8.93 \pm 0.08 \mathrm{c}$ & $5.63 \pm 0.06 \mathrm{c}$ & $2.52 \pm 0.01 \mathrm{c}$ & $54.1 \pm 0.3 \mathrm{~b}$ & $7.86 \pm 0.06 \mathrm{~b}$ & $18.18 \pm 0.01 \mathrm{c}$ \\
\hline
\end{tabular}

Mean $\pm \mathrm{SD}$; different letters within a column indicate significant differences $(p<0.05)$. WBC, water binding capacity; WHC, water holding capacity; OAC, oil absorption capacity 
Fig. 3 Typical mechanical spectra for doughs with three different particle sizes of apple pomace and two different replacement levels of AP. a Control. b $15 \%$. c $30 \%$. d( 4,3$)$, AP840 $=840 \mu \mathrm{m} ; \mathrm{AP} 482=$ $482 \mu \mathrm{m} ;$ AP362 $=362 \mu \mathrm{m}$

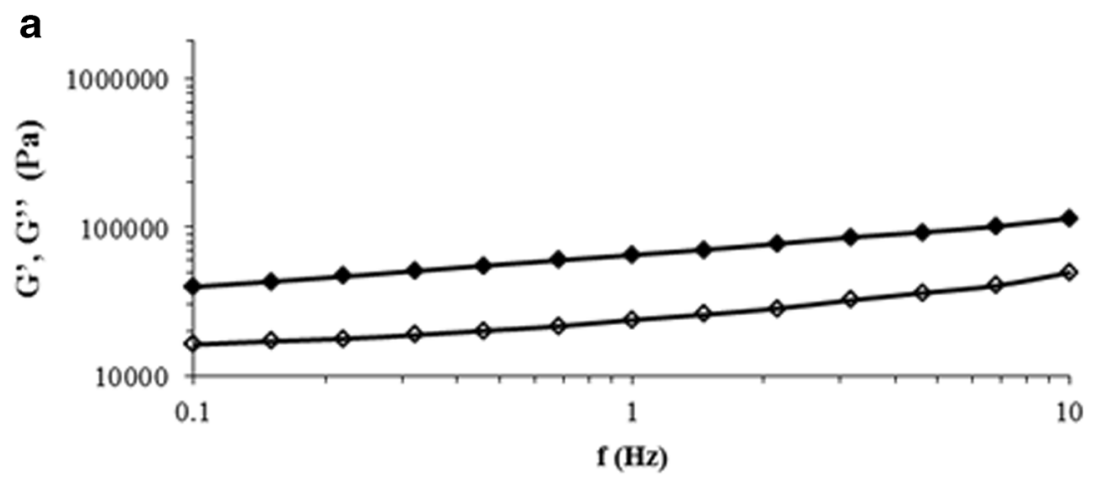

$\multimap G^{\prime} \multimap G^{\prime \prime}$

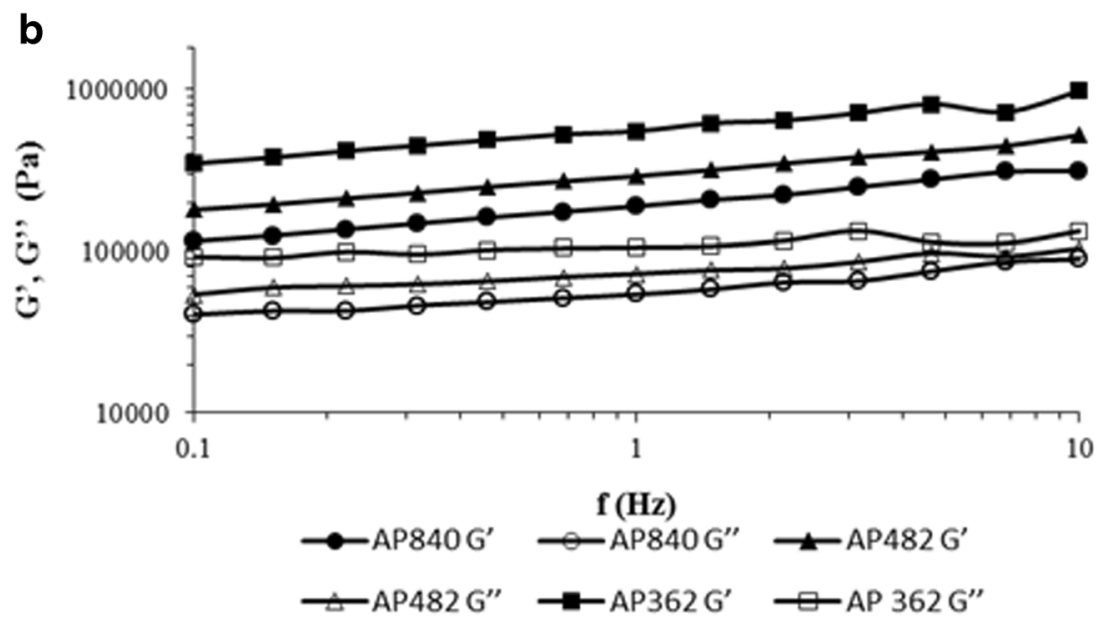

C

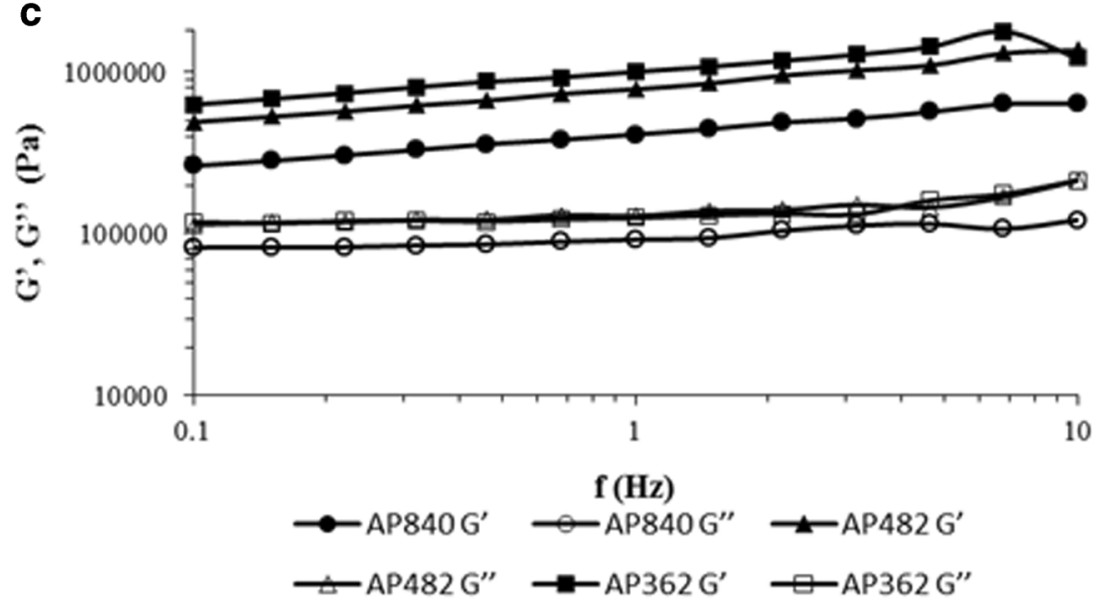

diameter, which is directly related to the spread ratio (SR), and the hardness, which depends on the cookie structure. The SR is likely affected by the water-binding components of the dough (Pareyt and Delcour 2008). For SR, the highest values were observed in the control sample. Comparatively, cookies with AP362 presented the lowest SR values, with significant differences $(p<0.05)$ with respect to the other formulations with AP 840 and AP482. A significant negative correlation $(r=-$ $0.9702, p<0.05$ ) was found between the SR of cookies and $G^{\prime \prime}$ of doughs. It was also observed that for the smallest particle size of AP used, there was no influence of the substitution level. However, a significant $(p<0.05)$ influence of the substitution 


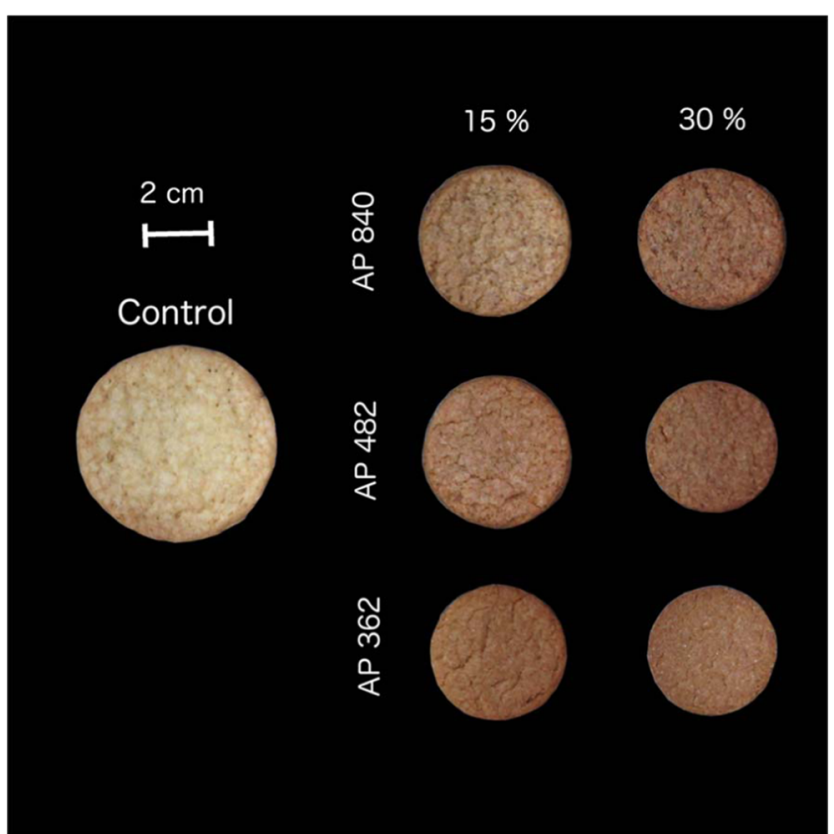

Fig. 4 Image of sugar-snap cookies made from wheat flour and AP. $\mathrm{d}(4,3), \mathrm{AP} 840=840 \mu \mathrm{m} ; \mathrm{AP} 482=482 \mu \mathrm{m} ; \mathrm{AP} 362=362 \mu \mathrm{m}$

level was observed for samples with AP840 and AP482; SR decreased when the level of substitution was $30 \%$, as is shown in Fig. 4. Cookies with $30 \%$ of WF replacement not only had lower SR but also a smoother and less cracked surface.

These results coincide with those reported by Toledo et al. (2017) and Naknaen et al. (2016), who pointed out that the incorporation of fruit by-products reduces the SR, due to the water absorption capacity of the fibers present in them. Similarly, Mancebo et al. (2018) reported a decrease in the SR in cookies in which wheat flour had been replaced with $15 \%$ of different insoluble fibers, and found a strong negative correlation between the water absorption properties and SR. In the present study, a significant $(p<0.05)$ negative correlation was found between the WHC of AP and SR of cookies at a 15\% level of replacement and between both water absorption properties (WHC/WBC) and SR at a 30\% level of replacement.

With respect to texture, it was found that all cookies enriched with AP were harder (higher maximum force $F$ ) than WF control $(31 \mathrm{~N})$, and the hardest cookies $(F=75-77 \mathrm{~N})$ were obtained with the AP of the smallest particle size. However, no clear trend was found in the rupture displacement $(\mathrm{mm})$. The $F$ value of cookies, obtained from the texture assays, significantly and positively correlated with the elastic and viscous moduli of dough $(r=0.9815, r=0.9788$, respectively, $p<0.05)$ and negatively with the loss tangent $(r=-0.9886, p<0.05)$, demonstrating the strong influence of the rheological parameters of dough on the hardness of the final product. Moreover, the spread of cookies during baking negatively correlated with $F$ $(r=-0.9136, p<0.1)$. These results are in agreement with those reported by other authors who replaced WF with different ingredients such as chickpea flour (Mieszkowska and Marzec 2016) or different soluble and insoluble fibers (Mancebo et al. 2018) in the preparation of cookies. Cookies prepared with finer flours were harder than those made with coarser flours, probably due to the more compact structure of cookies obtained with fine flours. These results are in agreement with Mancebo et al. (2015) who reported that the hardness was significantly affected by the particle size probably because cookies made from fine flour had a more compact structure. Sozer et al. (2014) reported the same trend for biscuits added with wheat bran of two different particle sizes. These authors found that fine bran incorporation increased the hardness of biscuits which visually exhibited a more compact structure than biscuits with coarse bran. In addition, biscuits with coarse bran were rougher and more easily broken down in sensory assays.

The results of color measurements are shown in Table 2 . The cookies with addition of AP were darker (lower $L^{*}$ value). Generally, the incorporation of a flour obtained from a fruit by-product in cookies leads to a reduction of $L^{*}$ values

Table 2 Cookie properties

\begin{tabular}{lllllll}
\hline & F max $(\mathrm{N})$ & Displacement $(\mathrm{mm})$ & Spread ratio & $L^{*}$ & $a^{*}$ & $b^{*}$ \\
\hline Control & $31.3 \pm 7.5 \mathrm{a}$ & $0.8 \pm 0.3 \mathrm{~d}$ & $8.3 \pm 0.5 \mathrm{~d}$ & $64.0 \pm 1.8 \mathrm{~d}$ & $1.6 \pm 0.7 \mathrm{a}$ & $18.3 \pm 1.2 \mathrm{e}$ \\
AP840 15\% & $48.7 \pm 3.9 \mathrm{~b}$ & $0.7 \pm 0.2 \mathrm{bcd}$ & $6.4 \pm 0.2 \mathrm{c}$ & $48.3 \pm 1.4 \mathrm{c}$ & $5.9 \pm 0.4 \mathrm{~b}$ & $13.5 \pm 0.8 \mathrm{~cd}$ \\
AP840 30\% & $49.2 \pm 7.9 \mathrm{~b}$ & $0.48 \pm 0.09 \mathrm{a}$ & $5.5 \pm 0.1 \mathrm{~b}$ & $42.7 \pm 1.1 \mathrm{a}$ & $6.0 \pm 0.3 \mathrm{bc}$ & $10.6 \pm 0.5 \mathrm{a}$ \\
AP482 15\% & $49.9 \pm 10.7 \mathrm{~b}$ & $0.50 \pm 0.08 \mathrm{ab}$ & $5.5 \pm 0.4 \mathrm{~b}$ & $46.6 \pm 0.7 \mathrm{~b}$ & $6.3 \pm 0.4 \mathrm{~cd}$ & $12.8 \pm 0.6 \mathrm{bc}$ \\
AP482 30\% & $63.0 \pm 7.9 \mathrm{c}$ & $0.6 \pm 0.1 \mathrm{abc}$ & $4.9 \pm 0.1 \mathrm{a}$ & $42.9 \pm 0.5 \mathrm{a}$ & $6.6 \pm 0.2 \mathrm{~d}$ & $11.0 \pm 0.5 \mathrm{a}$ \\
AP362 15\% & $74.6 \pm 6.3 \mathrm{~d}$ & $0.7 \pm 0.1 \mathrm{~cd}$ & $4.8 \pm 0.1 \mathrm{a}$ & $47.3 \pm 0.9 \mathrm{bc}$ & $6.6 \pm 0.2 \mathrm{~d}$ & $13.7 \pm 0.4 \mathrm{~d}$ \\
AP362 30\% & $77.7 \pm 6.9 \mathrm{~d}$ & $0.6 \pm 0.1 \mathrm{abcd}$ & $4.8 \pm 0.2 \mathrm{a}$ & $43.1 \pm 0.8 \mathrm{a}$ & $7.6 \pm 0.3 \mathrm{e}$ & $12.0 \pm 0.4 \mathrm{~b}$ \\
\hline
\end{tabular}

Mean \pm SD; different letters within a column indicate significant differences $(p<0.05)$ 
Fig. 5 Sensory scores of sugarsnap cookies substituted with $15 \%$ apple pomace flour of different particle sizes. $d(4,3)$, $\mathrm{AP} 840=840 \mu \mathrm{m} ; \mathrm{AP} 482=$ $482 \mu \mathrm{m} ;$ AP362 $=362 \mu \mathrm{m}$. Different letter above bars indicate significant differences among samples $(p<0.05)$

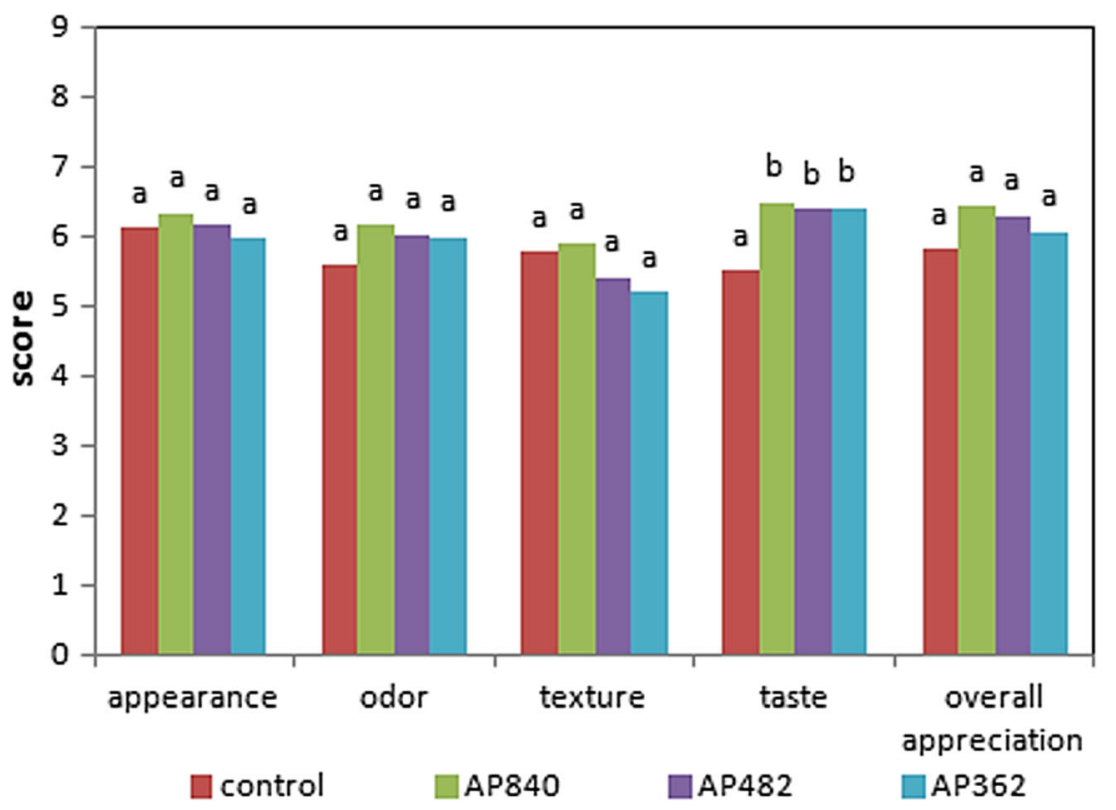

(Toledo et al. 2017). No clear trend was found at $15 \%$ of replacement; when the particle size decreases, the lightness also decreases. With $30 \%$ of replacement, the darkest cookies were obtained, and interestingly, there was no influence of the particle size of the AP, probably because the main factors for color development were browning reactions (Maillard reaction and caramelization) that depend on the sugar content.

When the parameter $a^{*}$ was evaluated, it was found that it presents positive values and a tendency to increase (i.e., a tendency to reddish values) when the AP particle size decreases. The lowest value of $a^{*}$ corresponded to the control cookie. The value of $a^{*}$ increased significantly by increasing the replacement level only for the smallest particle size (AP362). For all particle sizes, the value of $b^{*}$ increased significantly when the replacement level was higher.

\section{Sensory Acceptability}

The sensory evaluation was carried out only on the cookies with a $15 \%$ replacement level, since cookies with $30 \%$ replacement presented an excessively hard texture and also had an excessively sweet and bitter taste. The results of the cookie sensory evaluation are shown in Fig. 5. Although the particle size did not lead to significant differences in the texture, many evaluators said that they found those cookies with the smallest particle size harder and more compact. On the other hand, certain evaluators felt AP840 had a grainy texture, which was not considered unfavorable.

Although the addition of fruit and vegetable by-products generally decreases the global acceptability of breads, cookies, and cakes (Gómez and Martinez 2017), in the present work, no significant differences were observed with respect to the control cookie when the different parameters were evaluated, with the exception of the taste. When the taste of the cookies containing AP was evaluated, significantly higher scores than the control were obtained for cookies with AP (independently of the particle size).

\section{Conclusions}

Apple pomace (AP), a vegetable by-product rich in fiber that is generated in large quantities by the juice industry can be a good alternative for enriching different foods. Particularly, the results of the present work show that cookies can be successfully enriched and the replacement of wheat flour by $15 \%$ or $30 \%$ of AP could allow attaining levels of fiber of 3-6\% in the finished product. Sensory analysis demonstrated that the obtained product with a $15 \%$ of replacement had a level of acceptance similar to the control cookie and its taste obtained even a higher score than control. From a technological point of view, one of the main aspects to be taken into account for converting this by-product into an adequate food ingredient is the degree of grinding, since the particle size had a significant influence on dough and cookie attributes. Apple pomace of the greatest particle size rendered less hard cookies with a higher spread ratio which are desirable attributes. Moreover, the level of replacement of wheat flour with apple pomace is another important factor in order to attain a good balance between the enrichment with fiber and the technological quality. Each particular fruit by-product would deserve a specific evaluation of its potential as food ingredient but the results obtained with AP are encouraging respect to the use of this and other pomaces as sources of fiber for healthier foods. 
Acknowledgments The authors want to acknowledge the apple pomace donation by Jugos SA of Rio Negro, Argentina.

Funding Information This study is financially supported by the Spanish Ministry of Economy and Competitiveness (Project AGL2014-52928C2-2-R) and the European Regional Development Fund (FEDER) and the University of La Plata (Projects 11/X661 and 11/X771) and CONICET from Argentina.

\section{References}

AACC International. (2012). Approved methods of the American Association of Cereal Chemists International. Methods: 44e15.02 (moisture), 56-30.01 (WBC), 88-04 (WHC) (11th ed.). St Paul: American Association of Cereal Chemists.

ADA. (2002). Position of the American Dietetic Association: health implications of dietary fiber. ADA Reports, 102(7), 993-1000.

Ahmed, J., Al-Attar, H., \& Arfat, Y. A. (2016). Effect of particle size on compositional, functional, pasting and rheological properties of commercial water chestnut flour. Food Hydrocolloids, 52, 888-895.

AOAC. (1990). Official methods of analysis. In Association of Analytical Chemists. Washington, DC: AOAC.

Bhushan, S., Kalia, K., Sharma, M., Singh, B., \& Ahuja, P. S. (2008). Processing of apple pomace for bioactive molecules. Critical Reviews in Biotechnology, 28(4), 285-296.

Caparino, O. A., Tang, J., Nindo, C. I., Sablani, S. S., Powers, J. R., \& Fellman, J. K. (2012). Effect of drying methods on the physical properties and microstructures of mango (Philippine "Carabao" var.) powder. Journal of Food Engineering, 111(1), 135-148.

Chau, C. F., Wang, Y. T., \& Wen, Y. L. (2007). Different micronization methods significantly improve the functionality of carrot insoluble fibre. Food Chemistry, 100(4), 1402-1408.

Dayakar Rao, B., Anis, M., Kalpana, K., Sunooj, K. V., Patil, J. V., \& Ganesh, T. (2016). Influence of milling methods and particle size on hydration properties of sorghum flour and quality of sorghum biscuits. LWT - Food Science and Technology, 67, 8-13.

De La Hera, E., Martinez, M., \& Gómez, M. (2013). Influence of flour particle size on quality of gluten-free rice bread. LWT-Food Science and Technology, 54(1), 199-206.

Dhillon, G. S., Kaur, S., Brar, S. K., \& Verma, M. (2012). Potential of apple pomace as a solid substrate for fungal cellulase and hemicellulase bioproduction through solid-state fermentation. Industrial Crops and Products, 38(1), 6-13.

Elleuch, M., Bedigian, D., Roiseux, O., Besbes, S., Blecker, C., \& Attia, H. (2011). Dietary fibre and fibre-rich by-products of food processing: Characterisation, technological functionality and commercial applications: a review. Food Chemistry, 124(2), 411-421.

Gómez, M., \& Martinez, M. M. (2017). Fruit and vegetable by-products as novel ingredients to improve the nutritional quality of baked goods. Critical Reviews in Food Science and Nutrition, 0(0), 1-17.

Grover, S. S., Chauhan, G. S., \& Masoodi, F. A. (2003). Effect of particle size on surface properties of apple pomace. International Journal of Food Properties, 6(1), 1-7.

Guillon, F., \& Champ, M. (2000). Structural and physical properties of dietary fibres, and consequences of processing on human physiology. Food Research International, 33(3-4), 233-245.

Jung, J., Cavender, G., \& Zhao, Y. (2015). Impingement drying for preparing dried apple pomace flour and its fortification in bakery and meat products. Journal of Food Science and Technology, 52(9), 5568-5578.

Kohajdová, Z., Karovičová, J., Magala, M., \& Kuchtová, V. (2014). Effect of apple pomace powder addition on farinographic properties of wheat dough and biscuits quality. Chemical Papers, 68(8), 1059-1065.
Laguna, L., Sanz, T., Sahi, S., \& Fiszman, S. M. (2014). Role of fibre morphology in some quality features of fibre-enriched biscuits. International Journal of Food Properties, 17(1), 163-178.

Lavelli, V., \& Kerr, W. (2012). Apple pomace is a good matrix for phytochemical retention. Journal of Agricultural and Food Chemistry, 60(22), 5660-5666.

Leyva-Corral, J., Quintero-Ramos, A., Camacho-Dávila, A., de Jesús Zazueta-Morales, J., Aguilar-Palazuelos, E., Ruiz-Gutiérrez, M. G., Meléndez-Pizarro, C. O., \& de Jesús Ruiz-Anchondo, T. (2016). Polyphenolic compound stability and antioxidant capacity of apple pomace in an extruded cereal. LWT - Food Science and Technology, 65, 228-236.

Lin, M. J., Humbert, E. S., \& SosuIski, F. W. (1974). Certain functional properties of sunflower meal products. Journal of Food Science, 39(2), 368-370.

Lin, C., Pfaltzgraff, L. A., Herrero-Davila, L., Mubofu, E. B., Solhy, A., Clark, J., et al. (2013). Food waste as a valuable resource for the production of chemicals, materials and fuels. Current situation and global perspective. Energy \& Environmental Science, 6(2), 426-464.

Liu, J. C., Jiao, Z. G., Liang, X. H., Han, L., \& Liu, H. (2011). Effect of ultrafine pulverization on properties of apple pomace powder. Advanced Materials Research, 236-238, 2560-2563.

Mancebo, C. M., Picón, J., \& Gómez, M. (2015). Effect of flour properties on the quality characteristics of gluten free sugar-snap cookies. LWT - Food Science and Technology, 64(1), 264-269.

Mancebo, C. M., Rodríguez, P., Martínez, M. M., \& Gómez, M. (2018). Effect of the addition of soluble (nutriose, inulin and polydextrose) and insoluble (bamboo, potato and pea) fibres on the quality of sugar-snap cookies. International Journal of Food Science and Technology, 53(1), 129-136.

Mieszkowska, A., \& Marzec, A. (2016). Effect of polydextrose and inulin on texture and consumer preference of short-dough biscuits with chickpea flour. LWT - Food Science and Technology, 73, 60-66.

Moreira, R., Chenlo, F., Torres, M. D., \& Prieto, D. M. (2010). Influence of the particle size on the rheological behaviour of chestnut flour doughs. Journal of Food Engineering, 100(2), 270-277.

Naknaen, P., Itthisoponkul, T., Sondee, A., \& Angsombat, N. (2016). Utilization of watermelon rind waste as a potential source of dietary fiber to improve health promoting properties and reduce glycemic index for cookie making. Food Science and Biotechnology, 25(2), 415-424.

Nawirska, A., \& Kwaśniewska, M. (2005). Dietary fibre fractions from fruit and vegetable processing waste. Food Chemistry, 91(2), 221-225.

O'shea, N., Arendt, E. K., \& Gallagher, E. (2012). Dietary fibre and phytochemical characteristics of fruit and vegetable by-products and their recent applications as novel ingredients in food products. Journal of Agricultural Science and Technology, 16, 1-10.

Pareyt, B., \& Delcour, J. A. (2008). The role of wheat flour constituents, sugar, and fat in low moisture cereal based products: A review on sugar-snap cookies. Critical Reviews in Food Science and Nutrition, 48(9), 824-839.

Petrović, J., Fišteš, A., Rakić, D., Pajin, B., Lončarević, I., \& Šubarić, D. (2015). Effect of defatted wheat germ content and its particle size on the rheological and textural properties of the cookie dough. Journal of Texture Studies, 46(5), 374-384.

Quiles, A., Campbell, G. M., Struck, S., Rohm, H., \& Hernando, I. (2016). Fiber from fruit pomace: a review of applications in cereal-based products. Food Reviews International, 9129(November), 1-20.

Robertson, J. A., \& Eastwood, M. A. (1981). An examination of factors which may affect the water holding capacity of dietary fibre. British Journal of Nutrition, 45(1), 83-88.

Rocha Parra, A. F., Ribotta, P. D., \& Ferrero, C. (2015a). Apple pomace in gluten-free formulations: effect on rheology and product quality. International Journal of Food Science \& Technology, 50(3), 682-690.

Rocha Parra, A. F., Ribotta, P. D., \& Ferrero, C. (2015b). Starch-apple pomace mixtures: pasting properties and microstructure. Food and Bioprocess Technology, 8(9), 1854-1863. 
Rosell, C. M., Santos, E., \& Collar, C. (2009). Physico-chemical properties of commercial fibres from different sources: a comparative approach. Food Research International, 42(1), 176-184.

Schieber, A., Stintzing, F. C., \& Carle, R. (2001). By-products of plant food processing as a source of functional compounds - recent developments. Trends in Food Science and Technology, 12(11), 401-413.

Singh, A., Rana, I., Sahi, N. C., Lohani, U. C., \& Chand, K. (2012). Optimization of process variables for preparation of apple pomace - black soyflour based biscuits. International Journal of Food, Agriculture and Veterinary Sciences, 2(1), 101-106.

Sozer, N., Cicerelli, L., Heiniö, R.-L., \& Poutanen, K. (2014). Effect of wheat bran addition on in vitro starch digestibility, physicomechanical and sensory properties of biscuits. Journal of Cereal Science, 60(1), 105-113.

Sudha, M. L., Baskaran, V., \& Leelavathi, K. (2007). Apple pomace as a source of dietary fiber and polyphenols and its effect on the rheological characteristics and cake making. Food Chemistry, 104(2), 686-692.

Sudha, M. L., Dharmesh, S. M., Pynam, H., Bhimangouder, S. V., Eipson, S. W., Somasundaram, R., \& Nanjarajurs, S. M. (2016).
Antioxidant and cyto/DNA protective properties of apple pomace enriched bakery products. Journal of Food Science and Technology, 53(4), 1909-1918.

Toledo, N. M. V., Nunes, L. P., da Silva, P. P. M., Spoto, M. H. F., \& Canniatti-Brazaca, S. G. (2017). Influence of pineapple, apple and melon by-products on cookies: physicochemical and sensory aspects. International Journal of Food Science and Technology, 52(5), 1185-1192.

World Health Organization. (2003). Diet, nutrition and the prevention of chronic diseases. Technical report series \# 916. 1. Chapter 5. Geneva: World Health Organization.

Zucco, F., Borsuk, Y., \& Arntfield, S. D. (2011). Physical and nutritional evaluation of wheat cookies supplemented with pulse flours of different particle sizes. LWT - Food Science and Technology, 44(10), 2070-2076.

Publisher's Note Springer Nature remains neutral with regard to jurisdictional claims in published maps and institutional affiliations. 